значительно влияет на возможность сформировать мнение об оригинальном фильме и персонажах, а также угадать задумку режиссера. Следует помнить, что одни из самых важных функций кинематографа - информационная и коммуникативная - должны быть в полной мере переданы в дубляже, посредством адекватного перевода текста оригинала.

$* * *$

1. Комиссаров В. Н. Теория перевода (Лингвистические аспекты). - М.: Высшая школа, 1990 г. - 253 с.;

2. Виноградов В.С. Перевод. Общие и лексические вопросы. - М.: КДУ, 2004 г. - 226 с.;

3. Влахов С., Флорин С. Непереводимое в переводе. М.: Международные отношения, 1980. - 342 с.;

4. Любимов Н.А. Перевод. Английский каламбур. М., 2002. - 322 с.;

5. Казакова Т. А. Практические основы перевода. English $<=>$ Russian. - Изучаем иностранные языки. - СПб.: Издательство союз, 2011 г. - 320 с.;

6. Оболенская Ю.Л. Художественный перевод и межкультурная коммуникация. M.: URSS, 2013. 264 с.;

7. Снеткова М.С. Лингвостилистические аспекты перевода испанских кинотекстов (на материале русских переводов художественных фильмов Л. Бунюэля «Виридиана» и П. Альмадовара «Женщины на грани нервного срыва»): автореф. дис. ... канд. филол. наук. М., 2009.;

8. Чиж, М. С. Особенности перевода каламбура / М. С. Чиж, И. И. Данилова // Успехи современного естествознания. - 2012. - № 5. - С. 168.;

9. The Gentlemen (2019) Script. [Электронный ресурс] - 2019. URL: https://transcripts.thedealr.net/script.php/thegentlemen-2019-Z6qk (дата обращения: 03.10.21-24.10.21).

\title{
Степанова М.A. \\ Суггестивное речевое воздействие через оценочную номинацию на примере немецкого языка
}

МГИМО МИД России

(Россия, Москва)

doi: 10.18411/trnio-11-2021-206

\section{Аннотация}

В статье рассматривается семантический аспект суггестивности медийного дискурса на примере окказионального употребления сложной лексемы в немецком языке. Благодаря использованию в наименованиях семантического примитива, характеризующегося оценочностью, достигается суггестивный эффект текстов СМИ. В рамках законодательной и социальной тематики воздействие на читателя через словообразовательную модель с компонентом „gut“ преследует цель поддерживать положительное восприятие обществом некоторых мер в социальной сфере, в частности, закона KiQuTG. Однако эффект воздействия зависит от соотношения данной языковой реалии и её метаязыкового окружения, например, критики в публичном дискурсе, и экстралингвистических факторов.

Ключевые слова: суггестивность, дискурс СМИ, оценочность, семантика вторичной номинации, прагматика, интертекстуальность.

\section{Abstract}

The article examines the semantic aspect of the suggestiveness of media discourse on the example of the occasional use of a complex lexeme in German. Thanks to the use of a semantic primitive in the names, characterized by evaluativeness, a suggestive effect of media texts is achieved. Within the framework of legislative and social topics, influencing the reader through a word-formation model with a "gut" component aims to maintain a positive public perception of certain measures in the social sphere, in particular, the KiQuTG law. However, the effect of the influence depends on the ratio of a given linguistic reality and its metalinguistic environment, for example, criticism in public discourse, and extralinguistic factors.

Keywords: suggestiveness, media discourse, evaluativeness, semantics of secondary nomination, pragmatics, intertextuality. 


\section{Лингвистические аспекты суггестии и оценочности}

Понятие суггестии, или внушения, означает «непосредственное прививание психической сфере данного лица идеи, чувства, эмоции и других психофизических состояний, помимо его «я», т.е. в обход его сознающей и критикующей личности» [1]. Данный феномен достаточно широко исследован в таких сферах, как психология, политология, медицина и педагогика. Суггестивная лингвистика является относительно новым направлением в науке и определяется как «качественная лингвистическая теория, объясняющая воздействие языка на подсознание» [4, с.8]. Некоторые исследователи считают внушение и суггестию разными видами речевого воздействия, подчёркивая скрытый характер суггестии, при этом данное косвенное, замаскированное внушение воспринимается неосознанно и непроизвольно [5]. В нашем исследовании мы рассмотрим скрытую форму суггестии через оценочность с целью описать потенциал такого воздействия на общество. Речь пойдёт об оценочной номинации применительно к профессиональной юридической лексике, используемой за рамками юридического дискурса. Юридический термин «закон», которому изначально несвойственна оценочность, подвергается вторичной номинации во фразеологической единице и получает распространение в публичном дискурсе. Словосочетание, которое привлекло наше внимание, обозначает новый федеральный закон 2018 года, касающийся детских садов в Германии. «Закон о дальнейшем повышении качества и улучшении пользования дошкольными учреждениями и возможностей дневного ухода за детьми» (Gesetz zur Weiterentwicklung der Qualität und zur Verbesserung der Teilhabe in Tageseinrichtungen und in der Kindertagespflege (KiTa-Qualitäts- und Teilhabeverbesserungsgesetz - KiQuTG)) - в текстах СМИ встречается исключительно в сокращенном виде как „Gute-Kita-Gesetz“. В наименовании „Gute-Kita-Gesetz“ присутствует оценочность, тогда как в полном названии закона оценочность отсутствует. Роль вторичной номинации в данном случае заключается, с одной стороны, в упрощении подачи информации, с другой, - в косвенном воздействии на подсознание реципиента с целью формирования положительного восприятия мер, направленных на реализацию данного закона.

Лингвистическим выражением положительной характеристики выступает прилагательное „gut“ - «хороший». Семантика этого слова такова, что оно воспринимается в своём универсальном значении положительной оценки по отношению к охарактеризованному им объекту и относится к «семантическим примитивам» [2, с. 161]. Например, «хороший детский сад» - отвечающий современным запросам, предлагающий гибкий график работы для удобства родителей, обеспечивающий желаемые условия для ухода за детьми. Данные смыслы включены в понятие „Gute-Kita“ (,хороший детский сад“) и

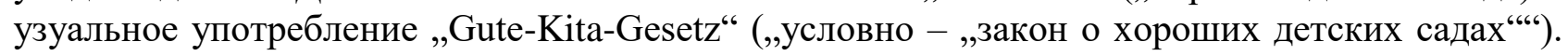
Таким образом, из „повышения качества“ и „улучшения“ в формулировке закона была образована вторичная номинация с прилагательным „хороший“. Причины такого словесного преобразования мы рассмотрим подробнее.

\section{Номинация и фразеология}

Номинация, которую мы понимаем как значимую для данного дискурса языковую единицу, служит для формирования понятия или концепта. Так как референты у понятия и концепта в нашем случае совпадают, мы будем считать их взаимозаменяемыми терминами в данной работе. С точки зрения немецкой культуры понятие «детский сад» можно считать одним из ключевых в представлении немцев об обществе. Авторы известной монографии о немецком менталитете и культуре посвящают концепту «детский сад» целую главу и отмечают, что во второй половине 19 века, когда слово было заимствовано английским языком из немецкого, оно приобрело популярность и стало настоящим экспортным продуктом [8, с. 249]. Это свидетельствует о том, насколько значимой для общества является тема детских садов и связанного с ними закона, регулирующего деятельность в социальной сфере. 
C точки зрения лингвистики интересующий нас фразеологизм „Gute-Kita-Gesetz“ не является юридическим термином, а представляет собой сложное слово, многокомпонентное существительное, состоящее из прилагательного, сокращения (аббревиатуры) и существительного. Такой способ словосложения характеризует данное словосочетание как узуальное сокращенное наименование.

Прагматический фактор играет существенную роль при выборе признаков, лежащих в основе номинации. Выступая как сигнификат имени, понятие включает в себя категориально-языковые признаки, в том числе экспрессивность, то есть отношение говорящего к содержанию [11, с.336]. Прагматика высказываний, содержащих наименование „Gute-Kita-Gesetz“, заключается в упрощении формулировки для удобства её употребления. Однако очевидно, что в результате замены некоторых компонентов и сокращения полного названия закона получилось употребление всей номинации в положительном ключе. Слово „Gesetz“ (закон) расположилось непосредственно близко к композиту „Gute-Kita“ и визуально воспринимается как одно целое с ним, при этом на подсознательном уровне закладывается положительное представление о детских садах, которые государство поддерживает на законодательном уровне. Наименование двух объектов и одного признака в одном словосочетании делает возможным перенос признака с одного объекта на другой по принципу ассоциации. То есть закон ассоциируется с тем, что хорошо, и поэтому скорее будет восприниматься положительно, чем если бы сокращенное наименование не имело в своём составе лексему „gut“ (,Kita-Gesetz“).

\section{Дискурс и речевое действие}

Если рассмотреть данное выражение с точки зрения теории речевых актов, то само наименование можно представить как локуцию, коммуникативное намерение сформировать положительный образ политики в отношении дошкольных учреждений иллокуцией, результат воздействия на сознание адресата - перлокуцией [3, с. 22-130].

Каким образом оценочность передаётся от говорящего к слушающему и как воздействует на него, определяется прагматическими, дискурсивными и метадискурсивными факторами. Дискурсивным фактором может быть коннотация внутри семантики слова: «хороший» в сфере дошкольных учреждений означает «качественный». Метадискурсивными средствами можно описать функционирование лексической единицы в дискурсе: предлагая определённую формулировку, автор воздействует на сознание реципиента, который так или иначе реагирует на это воздействие. Суггестивное воздействие осуществляется через многократное повторение слова в дискурсе СМИ, который является разновидностью публичного дискурса. Представители либеральной политической партии СвДП прокомментировали Gute-Kita-Gesetz следующим образом: это «лукавое название» (,Schummelbezeichnung“), вместо инвестиций в качество субсидируются родительские взносы, что никак не способствует повышению уровня дошкольного учреждения. Ответную реакцию Остин называет перлокутивным актом, который не должен совпадать с иллокуцией, но свидетельствует о том, как было понято данное речевое действие [6, с. 78].

Констатацию фактов Остин не относил к речевым действиям, так как считал, что невозможно только лишь констатировать что-то, каждое высказывание является частью естественного обмена высказываниями и несёт в себе намерение. Если это коммуникативное намерение нам непонятно, то мы спрашиваем говорящего, зачем он это говорит. Следовательно, коммуникативное намерение номинации «Gute-Kita-Gesetz» должно быть понятным, однако однозначным оно не является. Реципиент интерпретирует слова как лукавство, так как обозначаемое расходится с действительностью. Посредством скрытого суггестивного воздействия осуществляется попытка моделирования действительности через дискурс СМИ. Другими словами, в сознание реципиента закладывается понимание о называемом объекте как одновременно желаемом и действительном (детские сады должны стать хорошими, и то, что мы работаем в этом направлении - это уже хорошо). Здесь мы подходим к предмету исследования с другой стороны, a именно, со стороны интертекстуальности, так как речь идёт не просто о номинации, а о словообразовательной модели, которая просматривается в разных типах текстов. 


\section{Интертекстуальность и семантика}

Развивая идеи М. Бахтина о диалогичности всякого высказывания, Ю.Кристева вводит понятие интертекстуальности, обозначающее весь спектр межтекстовых отношений [6, с. 227]. Повторное упоминание, аллюзии, цитирование являются связующими элементами между разными текстами. Рассматриваемая номинация “Gute-Kita-Gesetz" отсылает к устойчивым словосочетаниям в других текстах, например, в документах $\mathrm{OOH}$ и Всемирного Банка есть термин "good governance” (нем. - ,gute Regierungsführung“), обозначающий «качественное» или «благое» управление, направленное на борьбу с коррупцией, бедностью и антидемократическими тенденциями $[6$, с. $1-2,10]$. В немецких СМИ с подачи некоторых политиков бытует выражение "gute Politik", бессодержательная декларативность (курсив автора статьи) которого прикрывает отсутствие конкретных практических решений. Использование семантического примитива "gut", апеллирующего к базовым представлениям о характере, качестве вещей и явлений, для номинации общественно важных явлений и его многократное употребление ведут к закреплению ассоциации положительного признака с названным явлением. Однако примеры показывают, что за положительной коннотацией словосочетаний с компонентом «хороший» могут стоять разные смыслы, и каждое из этих выражений требует интерпретации в контексте.

Представляется, что словообразовательная модель с компонентом "gut" используется в целях суггестивного воздействия на сознание реципиентов.

\section{Выводы}

Суггестия как неосознанное внушение является средством контроля сознания путём «тиражирования» определённых смыслов в публичном дискурсе. Это означает, что базовые понятия в сознании людей подвержены модификации через СМИ. Сокращённое узуальное наименование „Gute-Kita-Gesetz“ не является термином, но представляет собой словообразовательную модель на основе профессиональной лексики с использованием семантического примитива, прилагательного, с целью придания лексеме положительной коннотации для достижения метаязыковой цели, а именно - донести до сознания людей важность и пользу соответствующих политических мер.

$$
* * *
$$

1. Бехтерев М. В. Внушение и его роль в общественной жизни [Электронный ресурс]. СПб.: Издание К. Л. Риккера, 1908. Режим доступа: http://www.psylib.ukrweb.net/books/behtv01/txt27.htm (дата обращения: 05.10.21)

2. Вежбицкая А. Сопоставление культур через посредство лексики и прагматики. - М.: Языки славянской культуры, 2001. - 272 с. - (Язык. Семиотика. Культура. Малая серия).

3. Остин, Джон Лангшо. Слово как действие // Новое в зарубежной лингвистике. Вып. 17: Теория речевых актов. М., 1986. С. 22-130.

4. Черепанова И. Ю. Текст как фактор изменения установки личности (лингвистические аспекты суггестии): автореф. дис. ... канд. филол. наук. Пермь, 1992. 18 с.

5. Шелестюк Е. В. Речевое воздействие: онтология и методология исследования. Челябинск, 2008. 232 с. Режим доступа: https://vk.com/doc91377154_570395154?hash=bb586d30a6c1b3d17c (Дата обращения: 5.10.21)

6. Auer, P. Sprachliche Interaktion. Eine Einführung anhand von 22 Klassikern // Konzepte der Sprach- und Literaturwissenschaft, Tübingen, Max Niemeyer Verlag, 1999, 282 S., S. 70-79.

7. Good government practices for the protection of human rights // United Nations. - New York and Geneva, 2007, 94 p. Режим доступа: https://www.ohchr.org/Documents/Publications/GoodGovernance.pdf (Дата обращения: 5.10.21)

8. Dorn T., Wagner R. Die deutsche Seele. - München: Albrecht Knaus Verlag, 1. Aufl., 2011. — 560 S.

9. „Das Gute-Kita-Gesetz ist eine Schummelbezeichnung: Denn statt die ohnehin knappe Investitionssumme vollständig in die Qualität der frühkindlichen Bildung zu investieren, fließt ein viel zu großer Teil des Geldes in die Subventionierung von Elternbeiträgen“, sagt die stellvertretende FDP-Parteivorsitzende Katja Suding gegenüber WELT. „Kostenfreie Kitasleisten jedoch absolut keinen Beitrag für deren Qualität.“ - In: Die Welt: „Das Gute-KitaGesetz ist eine Schummelbezeichnung“. https://www.welt.de/politik/deutschland/article203719126/Kinderbetreuung-Gute-Kita-Gesetz-ist-eineSchummelbezeichnung.html

10. «Несмотря на согласие относительно важности качественного управления как основного фактора развития, разные организации по-разному это понимают» (перевод автора статьи). - URL: https://unu.edu/publications/articles/what-does-good-governance-mean.html (Дата обращения: 5.10.21)

11. Лингвистический словарь. Под редакцией В.Н.Ярцевой. М.: Советская энциклопедия, 1990, 688 с. 